\title{
Living with vesico-vaginal fistula: experiences of women awaiting repairs in Ebonyi State, Nigeria
}

\author{
UZOMA O. OKOYE ${ }^{1 *}$, NKECHI EMMA-ECHIEGU ${ }^{2}$ and PERPETUA L. TANYI ${ }^{3}$ \\ ${ }^{1}$ Department of Social Work, University of Nigeria, Nsukka, Enugu State, 410002, Nigeria \\ ${ }^{2}$ Department of Sociology/Anthropology, Ebonyi State University, Abakaliki, Nigeria \\ ${ }^{3}$ Department of Social Work, University of Nigeria, Nsukka, Nigeria
}

\begin{abstract}
Vesico-vaginal fistula (VVF) is one of maternal health problems confronting public health workers in Nigeria today. Information on how women suffering from this condition cope is important in that it can inform the design and delivery of programmes and interventions to address the challenges that face victims of VVF. The objective of this study was to highlight how women living with VVF cope with the health problem in Ebonyi state, Nigeria. In-depth interviews were conducted with ten women awaiting repairs at the National Fistula Centre at Abakaliki in Nigeria. Six of the women have lived with the health problem for more than ten years. Findings show that nearly all the women attributed their health problem to supernatural causes. The women stated that they go through a lot of physical and emotional problems. Some of the ways they have devised of physically coping with the problem include bathing regularly and use of strips of old wrappers as pads. Many of them cope emotionally and financially by attending religious gatherings and having some form of income yielding business. The study recommends the need for repairs to go hand in hand with vocational training so that they will have some income yielding business after repairs.
\end{abstract}

Keywords: vesico-vaginal fistula, coping strategies, experiences, Nigeria

\section{Introduction}

Worldwide two million women are living with vesico-vaginal fistula (VVF) with an annual incidence of 50,000 to 100,000 new cases (UNFPA, 2008). Nigeria accounts for about $40 \%$ of the annual global burden of VVF (UNFPA, 2008). These figures may be low because accurate prevalence rates of obstetric fistula are not easy to come by due to inaccurate reporting, underreporting and shame, which keep women from complaining about fistula (Miller et al., 2005). Fistula results in the constant leaking of urine through the vagina (Miller et al., 2005). Apart from continuous leakage of urine, VVF also often leaves its victims with foetal demise, cervical and pelvic damages, and neurological conditions such as foot-drop, urogenital infections, ammonia dermatitis, genital lacerations, kidney infections and amenorrhea (Hilton, 2003).

Researchers have put forward several factors that contribute to the incidence of VVF (Mela et al., 2007; Mohamed et al., 2009; Wall, 2012). Also the condition comes with a lot of discrimination and stigmatization. For instance the malodorous nature of VVF exposes its victims to mistreatment and stigmatization leading them to be ostracized by their husbands, families, and community (Pope et al., 2011). For example scholars have reported about family members not wanting women with VVF to share food at family events (Khisa \& Nyamongo, 2012). In addition, there are reports that that vaginal injuries sometimes result in a woman's inability to perform some house chores and marital obligation to her husband (Ahmed \& Holtz, 2007). In societies like Nigeria where a woman's worth is dependent on fulfilling her marital (sexual) duties, this situation is devastating. The lives of women with fistula are generally uneasy.

Interest in the processes by which people cope with various forms of illness or medical condition is one of the emerging areas of study in recent years (Andersson \& Hägnebo, 2003; Jemtå et al., 2007). Some of these studies have focused on various techniques and strategies that

\footnotetext{
* Correspondence: Uzoma O. Okoye; E-mail: uzoma.okoye@unn.edu.ng
} 
have been adopted by various classes of individuals in coping with all manner of life problems and conditions. In the same vein, Elzubeir et al. (2010) seem to suggest that the coping strategy adopted by an individual is determined by a number of factors such as gender, environment, cultural background and availability of supportive networks. This is also true for women living with fistula. Although many women with VVF may not live successful and happy lives, they have developed different coping strategies in order to have a relatively good life. These coping strategies' play an important role for managing their health condition. They include changes in lifestyle, acquisition of aids, and so on (WDP, 2006; Kabayambi et al., 2013).

Studies have reported that lifestyles changes among women with urinary incontinence include wearing outfits that can cover the visible sign of urine, carrying extra clothing always, frequent change of clothes, limiting physical activity, sexual abstinence and limiting water intake (Anders, 2000; Li et al., 2007; Delarmelindo et al., 2013). Some protective aids that these women use include home-made pads, toilet papers, towel and handkerchiefs (Diokno et al., 2004). There are other survival strategies adopted by women with VVF. According to Watt et al. (2013) many VVF patients use religion as a copying strategy. This is because some VVF victims believe that they are bewitched by some wicked or spiritual forces.

Most of the studies on VVF in Nigeria have addressed the socio-cultural and health system factors that predispose women to the condition, the implications of VVF on livelihoods, the clinical management of the condition and barriers to health-seeking behaviours of VVF patients (Harrison, 1983; Ojanuga, 1994; Aboyeji, 1997; Muneer-Deen et al., 2002; ljaiya et al., 2010). Poorly documented in the existing literature are VVF-afflicted women's direct accounts and experiences of living and coping with the condition. Owing to this gap in knowledge, very little about victims experiences as it relates to their strategies for coping with the condition is currently known. The main objective of this paper therefore was to document some of the lived experiences of VVF victims as well as their strategies for coping with the condition in Ebonyi State, Nigeria. It is believed that such information can inform the design and delivery of programmes and interventions to address the challenges that face victims of VVF.

\section{Materials and Methods}

\section{Study area}

This study involved women with VVF attending the National Fistula Centre located in Abakaliki the capital of Ebonyi State, Nigeria. The population of Ebonyi state is estimated to be about two million people with women and girls aged 13 and above forming $52 \%$ of the population (NPC, 2006). The 2008 National Demographic and Health Survey, indicates that many of women in Ebonyi State deliver their children at home and that their lives are characterized by poverty, powerlessness, illiteracy, poor access to maternal care services and lack of access to basic social services. Polygyny and child marriage are also widespread in the state (NPC, 2009).

\section{Sampling procedure}

The sampling of participants was based on the availability of respondents, and they were recruited using purposive sampling procedure. Participants had to be on admission awaiting repairs at The National Fistula Centre Abakaliki. Ten women gave their oral informed consent before participating in the taped interview. The interviews were carried out over a two week period in October 2010.

The interviews were conducted while the women were in hospital wards on admission before undergoing repair surgery. Each in-depth interview was conducted in a private room outside the ward. The interview lasted between 1-2 hours because some of respondents kept getting up to use the restroom, since some could not sit for a long time without using the restroom. The participant's level of openness during the in-depth interviews varied, as some of 
them were very free, open and relaxed, while a few others were still withdrawn and ashamed in narrating their experiences. With the permission of respondents, the interviews were tape recorded. A female note taker was used in case of technical failure with the recording gadget. All interviews were conducted in the local Izzi dialect. The interview guide consisted of a few questions about participants' experiences with fistula and means of coping with the condition. Interviews were largely participant-driven. However, the interview questions were used as a starting point from where participants were free to discuss the elements of their coping strategies with the condition and experiences that they found most significant.

\section{Data analysis}

The interviews were transcribed in the local Izzi dialect and then translated into English. As opined by Lopez et al. (2008) care was taken to ensure that context and nuances of language and choice of words used to explain certain circumstances, feelings and situations were not lost. Data analysis employed the phenomenological approach proposed by Creswell (2007) to sift out the lived experiences of the women. Themes were then built to facilitate identification of common and essential elements of coping with the condition as identified by the women. Specifically the themes were built from the following research questions: a) what does living with VVF mean for its victims? b) how do they describe the implications of the condition for their lives, relationships, and livelihood situations? c) what are the everyday coping strategies and self-care practices of VVF victims? Each theme was discussed and necessary illustrative quotes extracted to support views expressed.

\section{Ethical considerations}

The study instrument and methodology was approved by the Ethics Board of the Ebonyi State Teaching Hospital overseeing the Centre. Oral informed consent was sought and obtained from each participant prior to recruitment.

\section{Results}

\section{Demographic characteristics of participants}

The mean age of participants was 35 years. Three of the respondents were still married and two were single and had never married. Only one respondent did not have any formal education but two completed twelve years of schooling. Five respondents had lived with VVF for 12 years or more. Their average monthly income was about US\$57. Only three of the women had three children and above, while three had no children at all.

\section{Onset of VVF and perceived causes}

The women described VVF as a sudden change in their body functioning that makes them continuously leak urine uncontrollably. Many of the respondents explained that they could not understand what was happening to them. None associated the condition with prolonged/obstructed labour, though three women reported that they have now been told by doctors that it was child birth that caused it. However nearly all of them reported that at the onset, their family members were sympathetic and thought it was something that will stop after one week, but as time went on and the condition persisted, members of their family and neighbours started making comments that blamed them for the condition. A 29 year old respondent who has lived with VVF for six years said. "They even tell me that this disease is a reward from nature for all the evil things I did in my youth".

Another respondent stated that a neighbour had said to her, "If you want this sickness to stop, you must confess your infidelity and you will be free from this ailment". Another respondent blamed her condition on her mother-in-law. According to her, "My mother-in-law 
dislikes me as the son's wife and always threatened to deal with me, she used her witch-craft to attack me and kill my baby, and inflicted me with this disease to put me to shame". And yet another described her case thus: "I had my baby and there was umbilical cord around his neck and the problem started two days after that". In all these narratives, none of the respondent attributed the cause of her VVF condition to child birth.

\section{Lived experiences of VVF victims}

The women interviewed described their experiences of living with VVF in terms such as shameful, humiliating, misery and despondency. Other terms which they used to describe their lives with VVF include disempowerment, suffering, isolation, anger, depression and disappointment with life. These critical terms drove home the nuanced social, physical, psychological and other implications of VVF on the lives of responding women. From the narratives of the women, their physical experiences of living with VVF relates to the uncontrolled leakage and smell of urine. They described discomfort from physical symptoms such as soreness, irritation and itchiness in the genital area, general body pains, a burning feeling, constipation and painful blisters on their thighs due to constant wetness and friction. These blisters prevented them from walking for long distances, limiting their ability to complete chores or participate in social interactions away from home. One of the respondents put it thus: "The urine continues to pour and my whole cloth gets wet so easily, the smell is so humiliating with the pains from the sores on my thighs, I get tired easily, and this is not life". Yet another said: "this disease makes you feel weak and sick, the sores and blisters are so painful and you can't do much for yourself".

The worst suffering for these women may not be the physical manifestations of VVF or grief over the loss of their baby, but the social repercussions that follow. The VVF victims are often ostracized by their husbands, families and communities. The VVF victims expressed the misery associated with losing their dignity as women, mothers and wives. The women expressed how their friends, relations, children and even spouse generally avoided them saying that they have brought shame to them. The condition most often is considered as a sexually transmitted disease and viewed as a punishment from God for promiscuity. For the married ones, they were not allowed to cook food to avoid "urine entering" the cooking pot or to attend social functions. Their husbands avoided touching or having sexual intimacy with them and their families merely tolerated them.

Respondents reported emotional and psychological experiences of VVF indicating that, apart from mourning a dead child which is inevitable, they soon found themselves fighting for their own survival, social position and value in the society. Feelings they described as devastating and tormenting. Most also expressed a loss of self-esteem, depression, stress and anxiety. A few said that they actually wished they were dead rather than living a life of no dignity, no respect, low self-esteem and guilt for bringing shame to self, family, friends and community. One of the respondents narrated her experiences: "It is a shameful disease to be honest with you. It makes a neat woman to be smelly and causes her to be avoided like leper in the community. My husband did not send me away because of my children, but avoids touching or sleeping with me. My only daughter had a baby and I cannot go for the "omugo" (an Igbo traditional practice whereby a mother visits the home of her married daughter when she delivers a child in order to render help to her) because I did not want to embarrass her and her husband. It is so painful for me, because this is what every woman with a female child looks forward to". Some of the women worried about the stigma attached to VVF wished they will be given a "certificate" of good health to present back home so that they will be reintegrated into the community.

\section{Coping strategies used by VVF victims}

Respondents relied on many strategies to cope with their conditions and its attendant socioeconomic and psychological implications. To cope with the physical signs of the conditions (i.e. 
uncontrolled urination, soreness, irritation and itchiness in the genital area, general body pains, painful blisters on their thighs) the women living with VVF explained that they tried to maintain general neatness and feed well whenever they could afford it. They also used "calamine lotion" on the blisters. A respondent explained thus: "I try to bathe regularly with perfumed soap and powder to cover up the smell. I do not stay out long hours to prevent people from noticing the urine odour. Rubbing powder always on my inner thighs helps me walk well".

A respondent tried to explain how the "paw-paw leaves water' works. She said: "I collect paw-paw leaves and put in a pot filled with water and boil for some time. Then when it cools down, I use water from paw-paw leaves to bath and wash my thighs to reduce the itching and cool the rashes and sores". Yet another respondent tried to explain how she uses strips of old wrapper: "I get old wrapper and tear it into small pieces and this serves as pad because I cannot afford pampers. I use three strips together any day I am going out and I usually tie double wrapper to avoid soaking fast".

Women living with VVF are often at the risk of being divorced, viewed as outcasts, and denied participation in family and community as well as religious activities. To cope with these social repercussions that ensue, the women living with VVF explained the different things they did to cope emotionally. All the women mentioned religion as a very strong coping strategy. They said that they attend religious crusades and also visit pastors for counselling. A respondent said: “ $M y$ friends always invite me to any crusade where a strong man of God will come to see if I will receive miracle. I sometime visit my pastor to share my problems with him when it becomes too much for me and it helps me a lot because I feel better each time I discuss with him". Another said: "I am a member of St. Anthony's Association in my church; they normally come to visit me to pray and share fellowship with me. They also come with money and gifts of wrappers and food once in awhile. You know we need a lot of wrappers because urine makes wrapper to degenerate faster".

Most often women with VVF are abandoned by their families and left to fend for themselves financially. In this study, the women narrated how they coped with these experiences to include engaging in casual jobs to make extra money and going to markets where they are not known. The respondents described the VVF experience on their livelihood as life of dependency on relatives and others for survival because of their inability to fend and support themselves and their families economically. They also expressed concern about money to help in buying wrapper and soap to maintain basic hygiene of always washing their wrapper strips and wrappers. The VVF victims generally lived a life of poverty and struggle They coped economically by doing a lot of things, like working on other people's farms. A respondent explained: "I started selling rice in markets in nearby villages where I am not known, to make extra money, since nobody buys from me in our village". Another said: "I do not have a lot of money; I depend on my mother and, some of my family and church members to assist me financially and I sell firewood in the market to get some money too. Other women also earn money by working as labourers and doing such odd jobs as weeding because it is not as strenuous as cultivating".

Family members also play a big role in supporting some of these women living with VVF in their bid to earn a living. One respondent described how her mother supports her. She said: "I stay with my mother and I sell melon seeds to make money but my mother is the one that sell it for me because since it is edible no one will buy from me if I go to sell it myself". Another respondent said: "My family members asked me to be the only person in charge of harvesting the family owned palm-nuts from palm trees. From selling it I make some money to take care of myself and my children. I sell palm kernel too to make money". 


\section{Discussion}

Findings presented here came from ten women with VVF in Ebonyi State, Nigeria who shared their experiences on how they have been living and coping with the condition on a daily basis. This has helped in the understanding of the lived experiences of these women who had to devise means of coping with VVF. Our data regarding causes of VVF collaborated with what has been previously reported about women living with VVF (Mohamed et al., 2009; ljaiya et al., 2010; Khisa \& Nyamongo, 2012). Like findings from previous studies none of the ten women knew the actual cause of her condition rather they attributed it to supernatural causes. This still underscores the need for more enlightenment about VVF, its causes and ways of preventing it.

In the present study, findings suggest that the women go through physical and emotional problems as a result of the VVF condition. Physically the women reported that they had sores and blisters on their thighs due to constant wetness and friction. Some also reported feeling weak to attend to their routine chores. These findings confirm data from Bangser et al. (2011) who reported that women with VVF from Tanzania and Uganda suffer from genital sores and inflammation, and exhaustion, as well as an inability to walk normally. Apart from physical problems most of the women in this study reported that they suffered loss of dignity and social isolation. They took time to describe how they were treated by their family members, relatives and the community as a whole. The problem of social isolation of VVF patients have also been discussed in a number of studies (Yeakey et al., 2009; Pope et al., 2011; Khisa \& Nyamongo, 2012).

Our findings further show that these women have devised various ways of coping with VVF on a daily basis. These include, bathing regularly, using perfume and powder. The most popular method of coping was using old wrappers that are torn into strips as pads. All the women reported that they do this. This type of innovative method of coping has also been reported by Li et al. (2007) in a study among Chinese women with urinary incontinence. Apart from coping with the physical problems associated with VVF, the women also reported the use of religion as a means of coping. They engage in such activities as attending religious crusades and seeking the counsel of religious leaders. Similar findings have been reported elsewhere (Ano \& Vasconcelle, 2005; WDP, 2006; Watt et al., 2013; Kabayambi et al., 2013).

It is also important to note that none of these ten women reported being without some form of income. Some of them gathered firewood while some shelled melon or palm kernel. In all they engaged in these economic activities not because it is what they actually wanted to do but because of VVF. For instance one of the respondents noted that she was selling firewood because it is not edible. In other words a VVF patient may not be able to sell edible products. Previous studies elsewhere have also reported that VVF patients were not allowed to touch food (WDP, 2006; Khisa, \& Nyamongo, 2012).

Given the severe loss of self-esteem, stigma, discrimination, depression, stress and anxiety these women reported they experienced as a result of VVF, it is not surprising that some of them suggested the need to give them certificate of good health if they get repaired. The certificate will be proof that they have been fully repaired and can once more participate fully in community affairs. This goes to show how important it is for them to be reintegrated into community life. A report from Tanzania suggests that many women are still discriminated against even after repair (WDP, 2006). There may be need therefore for more community enlightenment in Ebonyi state that will focus on reintegration of VVF patients after repair. It may also be expedient to combine repair with acquisition of vocational skills by these women. This will go a long way in helping the women to get reintegrated quickly into the community since they will be self reliant.

Some methodological limitations which may influence findings are acknowledged. The first is that the women interviewed were neither a random nor representative sample. The use of only ten women who were found in the hospital awaiting repairs may have resulted in the 
selection of a non-representative sample. Also, no attempt was made to confirm the accuracy of these narrations since we felt it was the personal experiences of the women as they understood it. Nonetheless, our findings show that there is need for more concerted effort towards educating women about VVF and its causes. It is important to note that these women when they are eventually repaired will be faced with such challenges as economic and reintegration. Ahmed \& Holtz (2007) have noted the economic challenges that fistula survivors may face, and have called for intervention on the economic front as a vital component of reintegration. In Nigeria, Mohammad (2007) described a re-integration programme for fistula survivors in Northern Nigeria that incorporated economic empowerment. This type of community reintegration programme can also be introduced in South Eastern Nigeria where the present study was carried out. Vocational training for these women should be given priority too as this will help give them a sense of belongingness after having suffered discrimination for so long. The government should support these programmes that will ensure a complete rehabilitation and reintegration of these women. Family support as reported by Pope et al. (2011) is also important for women's reintegration. Family members are the last line of defense for women with VVF and it is only the support of family members that can help them to recover their lives and dignity. This study, therefore, recommends the need for repairs to go hand in hand with vocational training so that they will have some income yielding business after repairs.

\section{References}

Aboyeji, A.F. (1997) Obstetric performance of teenage primigravidae in Ilorin, Nigeria. Nigeria Medical Journal 33, 56-59.

Ahmed, S. \& Holtz, S.A. (2007) Social and economic consequences of obstetric fistula: life changed forever? International Journal of Gynecology and Obstetrics 99, S10-S15.

Anders, K. (2000) Coping strategies for women with urinary incontinence. Best Practice \& Research Clinical Obstetrics \& Gynaecology 14, 355-336.

Andersson, G. \& Hägnebo, C. (2003) Hearing impairment, coping strategies, and anxiety sensitivity. Journal of Clinical Psychology in Medical Settings 10, 35-39.

Ano, G.G. \& Vasconcelle, E.B. (2005) Religious coping and psychological adjustment to stress: a meta-analysis. Journal of Clinical Psychology 61, 461-480.

Bangser, M., Mehta, M., Singer, J., Daly, C., Kamugumya, C. \& Mwangomale, A. (2011) Childbirth experiences of women with obstetric fistula in Tanzania and Uganda and their implications for fistula program development. International Urogynecology Journal - and Pelvic Floor Dysfunction 22, 91-98.

Creswell, J.W. (2007) Qualitative Inquiry and Research Design: Choosing Among Five Approaches. Thousand Oaks, CA: Sage.

Delarmelindo, R.C.A., Parada, C.M., Rodrigues, R.A.P. \& Bocchi, S.C. (2013) Women's strategies for coping with urinary incontinence. Revista da Escola de Enfermagem da USP 47, 296-303.

Diokno, A.C., Burgio, K., Fultz, N.H., Kinchen, K.S., Obenchain, R. \& Bump, R.C. (2004) Medical and self-care practices reported by women with urinary incontinence. American Journal of Managed Care 10, 69-78.

Elzubeir, M.A., Elzubeir, K.E. \& Magzoub, M.E. (2010) Stress and coping strategies among Arab medical students: Towards a research agenda. Education for Health 23, 355.

Harrison, K.A. (1983) Obstetric fistula: one social calamity too man. Journal of Obstetrics and Gynaecology 90, 385-386.

Hilton, P. (2003) Vesico-vaginal fistulas in developing countries. International Journal of Gynecology and Obstetrics 82, 285-295. 
Ijaiya, M.A., Rahman, A.G., Aboyeji, A.P., Olatinwo, A.W., Esuga, S.A., Ogah, O.K., Raji, H.O., Adebara, I.O., Akintobi, A.O., Adeniran, A.S. \& Adewole, A.A. (2010) Vesico-vaginal fistula: A review of Nigerian experience. West African Journal of Medicine 29, 294-298.

Jemtå, L., Dahl, M., Nordahl, G. \& Fugl-Meyer, K.S. (2007) Coping strategies among Swedish children and adolescents with mobility impairment in relation to demographic data, disability characteristics and well-being. Acta Paediatrica 96, 1184-1189.

Kabayambi, J., Barageine, J.K., Matovu, J.K.B., Beyeza, J., Ekirapa, E. \& Wanyenze, R.K. (2013) Living with obstetric fistula: perceived causes, challenges and coping strategies among women attending the fistula clinic at Mulago Hospital, Uganda. International Journal of Tropical Disease and Health 4, 352-361.

Khisa, A. \& Nyamongo, I. (2012) Still living with fistula: an exploratory study of the experience of women with obstetric fistula following corrective surgery in West Pokot Kenya. Reproductive Health Matters 20, 59-66.

Li, F.L.W., Low, L.P.L. \& Lee, D.T.F. (2007) Chinese women's experiences in coping with urinary incontinence. International Journal of Urological Nursing 1, 112-119.

Lopez, G.I., Figueroa, M., Connor, S.E. \& Maliski, S.L. (2008) Translation barriers in conducting qualitative research with Spanish speakers. Qualitative Health Research 18, 1729-1737.

Mela, G.S., Massa, A.A., Yahaya, U.R., Bukar, M., Kizaya, D.D. \& El-Nafaty, A.U. (2007) Risk factors for obstetric fistula in North-Eastern Nigeria. Journal of Obstetrics and Gynaecology $27,819-823$.

Miller, S., Lester, F., Webster, M. \& Cowan, B. (2005) Obstetric fistula: A preventable tragedy. Journal of Midwifery and Women's Health 50, 286-294.

Mohammad, R.H. (2007) A community program for women's health and development: implications for the long-term care of women with fistulas. International Journal of Gynecology and Obstetrics 99, 138-142.

Mohamed, E.Y., Boctor, M.F.A., Ahmed, H.A., Seedahmed, H., Abdelgadir, M.A. \& Abdalla, S.M. (2009) Contributing factors of vesico-vaginal fistula (VVF) among fistula patients in Dr. Abbo's National Fistula \& Urogynecology Centre - Khartoum. Sudanese Journal of Public Health 4, 259-264.

Muneer-Deen, A.I., Abiodun, P.A. \& Zainab, B.B.I (2002) Epidemiology of vesico-vaginal fistula at the University of Ilorin Teaching Hospital, Nigeria. Tropical Journal of Obstetric Gynaecology 19, 101-103.

NPC (2006) Census Report. National Population Commission, Abuja, Nigeria: Government Printer.

NPC (2009) Nigeria Demographic and Health Survey 2008. Abuja, Nigeria: National Population Commission and ICF Macro.

Ojanuga, D.O. (1994) Social work practice with childbirth-injured women in Nigeria. Health and Social Work 19, 120-124.

Pope, R., Bangser, M. \& Requejo, J.H. (2011) Restoring dignity: social reintegration after obstetric fistula repair in Ukerewe, Tanzania. Global Public Health 6, 859-873.

UNFPA (2008) Report of the workshop on the reduction of maternal mortality in Ebonyi State. Workshop organized by the Office of the Wife of The Executive Governor of Ebonyi State in collaboration with UNFPA. New York: UNFPA.

Wall, L.L. (2012) A framework for analyzing the determinants of obstetric fistula formation. Studies in Family Planning 43, 255-272.

Watt, M., Wilson, S., Mercykutty, M., Masenga, G., MacFarlene, J. \& Sikkema, K. (2013) Religious Coping among Women With Obstetric Fistula in Tanzania. Paper presented at the $141^{\text {st }}$ of the American Public Health Association in Boston MA. Available at: https://apha.confex.com/apha/141am/webprogramadapt/Paper284040.html

WDP (2006) Risk and Resilience: Obstetric in Tanzania. an overview of findings and recommendations from the study. Women's Dignity Project, Tanzania and Engender 
Health USA. Available at: http://www.engenderhealth.org/files/pubs/maternal-health/riskand-resilience- obstetric-fistula-in-tanzania.pdf.

Yeakey, M.P., Chipeta, E., Taulo, F. \& Tsui, A.O. (2009) The lived experience of Malawian women with obstetric fistula. Culture, Health \& Sexuality 11, 499-513. 